IOS Press

\title{
Global issues facing the ITP community
}

\section{Shirley Watson}

The ITP Support Association, Synehurste, Kimbolton Road, Bolnhurst, Bedfordshire, MK44 2EW, UK

Tel.: +44 (0) 1234376 559; E-mail: shirley@itpsupport.org.uk

\section{Introduction}

The ITP Support Association (UK) was founded in 1995. My son had been diagnosed with ITP 3 years earlier at the age of 9 , and his platelet count had remained stubbornly low despite various treatments. His pædiatrician, on searching through the literature to find details of an ITP support group, discovered that none existed in the UK - or indeed, anywhere in the world! My despair was only too clear and in response he suggested that I should start one.

As the months turned into years my need to be in contact with other parents of ITP children became more intense and with the encouragement of my husband I decided to take the pædiatrician's suggestion seriously. Accordingly I contacted a medical question programme on the BBC and after my intention to start an ITP patient and parent group was read out, the telephone immediately began to ring with the first of 52 calls from various people with some ITP connection. That was the birth of the ITP Support Association!

The internet was in its infancy at the time so medical reference books in the local library were the only source of further information for those diagnosed with ITP that is, for those who felt brave enough to wade through abstruse and unfamiliar medical terminology.

The Association's primary task was the same then as it is now: to provide patient friendly information about ITP - what it is, what causes it, what are its treatments and what are the outcomes. Its secondary function was to provide a contact network for those with ITP to support and encourage one other. Later in its evolution the Association also filled another unmet need by funding research into ITP.

The story of the ITP Support Association can therefore be told in three sections. These are: (1) to inform and educate, (2) to offer support and sympathy, (3) to fund ITP research. As the following description emphasizes, these three goals are all integral parts of the same principal aim of the Association - to support ITP patients in their effort to maintain a healthy, active life. 


\section{Inform and educate}

Immune thrombocytopenic purpura is not hereditary. In common with other autoimmune diseases ITP can develop at any age, yet unlike some other autoimmune conditions it is not progressive. Importantly however, it does carry a risk of major hæmorrhage from the outset. The vast majority of patients (or parents of ITP children) have never heard of this rare disease and on diagnosis it presents a name that is very difficult to remember. Consequently it is common for them to experience a myriad of emotions which include fear and isolation. Although a minority of people prefer to remain in ignorance about their condition, it is no longer commonplace for the patient to leave all responsibility for their health matters to their doctor. Knowledge empowers, and this is particularly pertinent to ITP where there is no cure, no one treatment is effective for everyone and many treatments have side effects that can be worse than the disease itself. Those who strive to learn more about their ITP are therefore more able to make informed choices about the direction of his or her ITP management.

\subsection{Publications}

The Association's core booklet, Know About ITP, first published in 1996, began as a simple brochure outlining basic facts about the condition. It described the two main treatments available at that time, steroids and intravenous immunoglobulin, and included a couple of case histories of patients with ITP. It has since developed into a more comprehensive publication as new treatments became available and the Association has been able to collate information from its membership, medical advisory team and other external sources.

The Association's numerous current publications attempt to cover numerous aspects of ITP and also to inform readers about the many questions that so often arise. They contain explanations about the disease itself, known causes, diagnosis, ITP in children, ITP in adults, diagnosis, management and treatment, alternative therapies, dentistry, associated diseases, menstruation and pregnancy. These are supplemented by advice on what constitutes an emergency, over-the-counter drugs to be avoided, how to obtain a second opinion, injections and vaccinations, plus paragraphs on general outlook and lifestyle issues.

Almost half of the Association's additional publications (69 at the time of writing) have been written by the Association's US medical advisors, Professor James N. George and Professor George Buchanan. The variety of issues covered indicate the extent to which ITP bites into everyday life, from topics as diverse as, Can I die from ITP? to, Are alternative and herbal remedies safe? Complementing these are contributions by the UK medical advisors, Profs Adrian Newland and Ian Greer; Drs Paula Bolton-Maggs, Drew Provan and John Grainger, and by various doctors and ITP specialists on issues associated with ITP. 
Fellow trustee Keith Lewis and I have also produced factsheets which include advice on holidays, travel insurance, school attendance and disability benefits. The latest publication compiled with the help of the medical advisory team is a treatment table that lists all drugs currently used in the management of ITP, their method of administration, how they work, and the main side effects that may arise.

\subsection{A lifeline}

It has always been the policy of the ITP Support Association to provide evidencebased information rather than anecdotal opinion, although this is not so easy with a disease that is diagnosed primarily by the exclusion of other conditions! The Association's quarterly publication, The Platelet (edited by Keith Lewis), is often described by its readers as a lifeline. It has undergone a metamorphosis since the first edition in 1996, changing from an informal, chatty newsletter that kept the early membership up to date with the Association's work, to a respected journal today that includes serious articles, advice and comment by the world's leading ITP specialists. Patient case histories and queries are followed by a considered reply from one of the ITP medical advisory team. Reading about a life-threatening bleeding episode may help to alleviate a sense of isolation in a chronic, severe ITP sufferer, but it can indeed strike terror in the heart of a newly diagnosed patient if they don't also read that this is a very rare occurrence, that in all probability won't happen to them. Likewise, a reader's letter claiming a magic, but unproven, 'cure' for ITP essentially requires a balancing comment to avoid falsely raising hopes. The Platelet recently celebrated its 50th edition, a mark of its continuing success as a critical resource not only for ITP patients but also for physicians.

\subsection{The website}

In many respects the growth of the internet has been responsible for the emergence of the informed patient, but for the average person searching the web it is very difficult to assess the credibility of information given. The ITP Support Association's website www.itpsupport.org.uk (managed by Howard Anderson) provides an on-line overview of ITP with links to authoritative sources of information. It outlines the Association's research funding and (of course!) offers the opportunity to make a donation. It also features fundraising pages about friends of the Association who are undertaking sponsored events.

Whereas in the early days of the Association those joining the membership heard of the charity via word-of-mouth, leaflets available from hospitals or a mention in the media, today most find out about this charity from the official website.

\section{Support and sympathy}

Rare diseases often cause a feeling of alienation: 'How did I get this unheard of disease?' 'How can my family, friends and employer understand how I feel?' These 
are common complaints from those with ITP. And for some, especially children, it may also be, 'Why me?'

\subsection{Contact network}

For those who may need an empathetic ear, 3-4 patient/parent volunteers are available by telephone or e-mail. The Association also holds contact details of a few parents and partners bereaved through ITP who are willing to offer sympathy and understanding to help others cope with their loss.

\subsection{Conventions}

In 1998, three years after its formation, the Association held its first public meeting. Although ITP Patient Conventions are only held annually, feedback shows that these are greatly valued by all who attend. Those with ITP and their families can learn much about their condition from the eminent speakers' presentations and the discussion groups, but equally the speakers report that they learn much from the patients! Social time is also very important at these events as, being a rare disorder, it is usually the only occasion when those with ITP meet one another. People so often comment with surprise, 'Everyone looks so well!'

\subsection{Medical seminars}

Having assembled the world's foremost ITP specialists for patient conventions, it was a logical step to plan a second day's meeting for health professionals. The first Medical Seminar in 2004 was attended by over 100 hæmatologists and pædiatricians astonishing perhaps for a rare condition, but as the Association's Honorary President, Professor Sir John Lilleyman, pointed out, this may be an indication of just how problematical ITP can be for clinicians to manage.

\section{Funding ITP research}

From the outset the Association decided against charging a membership fee, relying instead on the generosity of members to fund its work through spontaeous donations although to cover postal charges a minimum annual donation is invited from the overseas membership. Drug companies who produce immunoglobulins (used as one of the first line treatments for ITP) have been generous in their joint sponsorship of the quarterly Platelet and the annual Conventions, and in the last couple of years they have been joined by two other pharmaceutical companies manufacturing new treatments for ITP. The Association was run entirely by volunteers until the end of 2008 when a part time administrative assistant with a scientific background and charity experience was appointed to help cope with the ever increasing workload. 
So many patient requests for information about ITP are usually followed by an enquiry as to what research is being done into the disease. Most understand that without research there is little hope of a cure. There has also emerged a clear need for a medical follow-up of patients in order to establish an ITP registry; no database was available to show how many people developed ITP, went into remission, died from severe haemorrhage, or had any particular treatment.This led the Association to initiate a research fund in 1999 which, with incredibly enthusiastic support from the ITP community, was able the following year to start providing funding for specific ITP projects.

\subsection{Projects funded}

During the last eight years $£ 5,000$ has been given towards Dr Bolton-Maggs study of newly diagnosed children with ITP, $£ 37,000$ to Dr Provan for his molecular analysis of treatment predictors in ITP, $£ 7,000$ to fund a clinical specialist ITP nurse working part time for one year, and $£ 10,000$ to fund the pilot year of the Adult ITP Registry. Additionally $£ 30,000$ has been awarded (over three years) to initiate and continue Dr John Grainger's Childhood ITP Registry, $£ 10,000$ to fund the UK component of Professor Victor Blanchette’s Quality of Life study and $£ 39,000$ to sponsor a scientist working full time analysing patient samples and data at the Royal London Hospital.

\subsection{ITP surveys}

In its 13 year history the ITP Support Association has carried out three surveys of its membership, the most recent conducted in September 2007. Initiated by Dr John Grainger, this lifestyle survey was developed and designed by Howard Anderson and Shirley Watson to create a 43 question closed-field survey addressing social engagement, work and school performance, sports and activities, symptoms, treatment, and travel. Completed surveys numbered 790 representing $45 \%$ of the Association's membership, 86\% of whom resided in England. Some interesting results emerged: $29 \%$ of patients reported missing work or school owing to fatigue (a common ITP symptom often not acknowledged by clinicians); 30\% of adults had elective surgery delayed because of low platelet counts; $29 \%$ of respondents had difficulty obtaining travel or life insurance; $35 \%$ of children and $19 \%$ of adult females had encountered suspicion about their bruising, which can be mistaken for marks of physical abuse.

\section{ITP links worldwide}

Those with troublesome ITP frequently ask about the treatments in other countries in the vain hope that a reliable cure exists somewhere else in the world. However it 
is apparent from the international ITP specialists with whom the Association collaborates that incidence and management is much the same throughout the developed world. Two ITP groups now exist in the US: the PDSA founded in 1998 and the Daisy Foundation in 1999; others have also emerged in Europe. In June 2008 the Association hosted an inaugural meeting of European ITP support organisations from Holland, Germany, Sweden and Denmark. A common theme soon emerged, that on diagnosis of ITP, sufferers felt alone and were without adequate knowledge and support. It was this that provided the impetus to form each of these groups to help adults and children diagnosed with Immune Thrombocytopenic Purpura. An ITP Europe website www.itpsupport.eu has now been launched linking to the 5 European group websites.

\section{Conclusion}

Following the initial realisation in 1995 that more information was needed for the support of patients with ITP and for parents of children with ITP, the ITP Support Association has become a respected international resource for patient/clinician support, education and research. The lesson learned from the 14 year history of the ITP Support Association is that active participation of patients and their families is essential to assist progress for greater understanding of this rare disease.

The future is exciting, with new treatments for ITP becoming available and the increasing collaboration of the worldwide patient groups who are able to share their success in supporting patients with an uncommon, but life-altering and challenging condition.

\section{Acknowledgement}

Conflict of interest: The ITP Support Association receives unrestricted educational grants from Amgen, Baxter BioScience UK, Bio Products Laboratories, CSL Ltd, GlaxoSmithKline, Grifols UK Ltd and Octapharma. 